\title{
Improving the Quality of Thematic Learning through the Discovery Learning Model in Class V SDN Legok Kebasen Students
}

\author{
Yuni Widyastuti \\ SD Negeri Legok Kebasen \\ Yuniwidyastuti38@gmail.com
}

\section{Article History}

accepted 01/11/2020

approved 08/11/2020

published $15 / 11 / 2020$

\begin{abstract}
The background of this research is the low quality of thematic learning and the use of less varied methods. The aim of this Classroom Action Research is expected to improve the quality of thematic learning through the Discovery Learning model for fifth grade students of SDN Legok Kebasen. This Classroom Action Research was conducted in 2 cycles, each cycle consisting of four stages, namely planning, implementing, observing and reflecting. The implementation of the action uses the Discovery Learning model with a systematics of initial activities, core activities and final activities. The results showed that students' learning completeness increased from $47.62 \%$ in the initial study to $66.67 \%$ in the first cycle and $90.48 \%$ in the second cycle. Student activity also increased from 23.86 in the initial study to 24.95 in the first cycle and 27.38 in the second cycle. The class average increased from 61.43 in the initial study to 70.00 in the first cycle and 75.24 in the second cycle. From the research results it can be concluded that the application of the Discovery Learning model can improve the quality of learning.
\end{abstract}

Keywords: Thematic Learning, Quality of Learning, Discovery Learning Model

\begin{abstract}
Abstrak
Penelitian yang dilakukan dilatarbelakangi oleh rendahnya kualitas pembelajaran tematik dan penggunaan metode yang kurang variatif. Tujuan Penelitian Tindakan Kelas ini diharapkan dapat meningkatkan kualitas pembelajaran tematik melalui model Discovery Learning pada siswa kelas V SDN Legok Kebasen. Penelitian Tindakan Kelas ini dilaksanakan dalam 2 siklus, masing-masing siklus terdiri dari empat tahap yaitu perencanaan, pelaksanaan, observasi dan refleksi. Pelaksanaan tindakan menggunakan model Discovery Learning dengan sistematika kegiatan awal, kegiatan inti dan kegiatan akhir. Hasil penelitian diperoleh ketuntasan belajar siswa meningkat dari 47,62\% pada studi awal menjadi 66,67\% pada siklus I dan 90,48\% pada siklus II. Keaktifan siswa juga meningkat dari 23,86 pada studi awal menjadi 24,95 pada siklus I dan 27,38 pada siklus II. Rata-rata kelas naik dari 61,43 pada studi awal menjadi 70,00 pada siklus I dan 75,24 pada siklus II. Dari hasil penelitian dapat disimpulkan bahwa penerapan model Discovery Learning dapat meningkatkan kualitas pembelajaran.
\end{abstract}

Kata kunci : Pembelajaran Tematik, Kualitas Pembelajaran, Model Discovery Learning

Social, Humanities, and Education Studies (SHEs): Conference Series https://jurnal.uns.ac.id/shes

p-ISSN 2620-9284 e-ISSN 2620-9292 


\section{PENDAHULUAN}

Pendidikan di sekolah dasar merupakan dasar pendidikan yang menjadi landasan bagi tingkat selanjutnya. Dari sekolah dasarlah proses pencerdasan anak bangsa dimulai. Oleh karena itu pendidikan di sekolah sasar merupakan satu jenjang pendidikan yang strategis.

Proses pembelajaran dalam Kurikulum 2013 harus menampakkan proses pembelajaran yang memungkinkan peserta didik berlatih mengembangkan ketrampilan kritis, sehingga dapat meningkatkan hasil belajar peserta didik.

Penerapan model pembelajaran inovatif dapat meningkatkan kualitas pembelajaran meliputi keterampilan guru, aktivitas siswa, dan hasil belajar siswa yang mendorong keterlibatan siswa secara aktif dalam pembelajaran. Pembelajaran inovatif mengutamakan peran guru sebagai fasilitator, motivator, dan evaluator disamping informator.

Keterlibatan siswa secara aktif dalam pembelajaran dan pengembangan kemampuan berpikir kritis siswa dapat ditingkatkan melalui penerapan model Discovery Learning. Discovery Learning merupakan model pembelajaran yang tepat untuk melatih dan mengembangkan keterampilan berpikir kritis dan rasa percaya diri siswa selama pembelajaran di kelas. Hosnan (2014: 282) menjelaskan pembelajaran Discovery Learning adalah suatu model untuk mengembangkan cara belajar siswa aktif dengan menemukan sendiri, menyelidiki sendiri, maka hasil yang diperoleh akan setia dan tahan lama dalam ingatan, tidak akan mudah dilupakan siswa. Melalui kegiatan belajar penemuan, anak juga bisa belajar berpikir analisis dan mencoba memecahkan sendiri problem yang dihadapi. Kebiasaan ini akan ditransfer dalam kehidupan bermasyarakat.

Hasil refleksi peneliti pada saat melaksanakan pembelajaran di kelas VA SDN Legok Kebasen dengan menerapkan Kurikulum 2013 tema Ekosistem ditemukan kendala, ditunjukkan guru belum melaksanakan pembelajaran inovatif sehingga siswa cenderung hanya menghafal materi yang diajarkan, guru belum menerapkan model pembelajaran mandiri berupa penemuan konsep sendiri, siswa hanya menerima tanpa ikut menemukan informasi secara mandiri. Pembelajaran kurang melibatkan siswa secara aktif yang mengakibatkan siswa hanya menjadi objek pembelajaran.

Permasalahan pembelajaran tersebut ditunjukkan dengan pencapaian hasil belajar siswa yang masih di bawah Kriteria Ketuntasan Minimal (KKM) sekolah yaitu 65. Data hasil belajar siswa menunjukkan bahwa siswa kelas VA SDN Legok Kebasen kurang memahami materi yang ditunjukkan dengan data, dari 21 siswa terdapat 11 siswa (52,38\%) memperoleh skor di bawah KKM dan 10 siswa (47,62\%) yang mendapatkan skor di atas KKM . Berdasarkan data hasil belajar tersebut, maka dibutuhkan suatu tindakan yang ditujukan untuk mengatasi permasalahan pembelajaran serta meningkatkan kualitas pembelajaran tematik.

Peneliti bersama kolaborator menetapkan model pembelajaran inovatif yang dapat meminimalisasi permasalahan pembelajaran dan meningkatkan kualitas pembelajaran tematik yaitu dengan penerapan model Discovery Learning melalui Zoom Meeting. Hal tersebut dikarenakan melalui model Discovery Learning dapat melatih siswa belajar secara aktif, analitis, terampil merumuskan dan memecahkan permasalahan melalui kegiatan penemuan informasi sendiri serta memfasilitasi kemampuan siswa untuk berpikir dan mempresentasikan apa yang dipahami sesuai 
dengan tingkat perkembangannya sehingga pembelajaran menjadi lebih bermakna. Kualitas pembelajaran diartikan sebagai indikator penentu keberhasilan pembelajaran. Menurut Hamdani (2011:295) kualitas pembelajaran adalah kualitas implementasi program yang telah dirancang sebelumnya. Depdiknas (2004: 7-10) menyatakan kualitas pembelajaran terdiri dari beberapa komponen: (1) keterampilan guru; (2) materi pembelajaran; (3) iklim pembelajaran; (4) media pembelajaran; (5) aktivitas siswa; dan (6) hasil belajar. Penelitian ini mengkaji komponen tersebut dalam 3 (tiga) variabel penelitian, meliputi: keterampilan guru, aktivitas siswa, dan hasil belajar siswa.

Adapun penelitian yang mendukung pemecahan masalah tersebut adalah penelitian yang dilakukan oleh Candra Diah Agustianasari pada tahun 2015 dengan judul "Peningkatan Kualitas Pembelajaran IPS Melalui Model Discovery Learning Berbantuan Media Audiovisual Pada Siswa Kelas VB SDN Ngaliyan 01 Semarang" menunjukkan bahwa pembelajaran dengan menggunakan model Discovery dapat meningkatkan aktivitas guru dan siswa serta hasil belajar siswa.

Berdasarkan penjelasan di atas, peneliti mencoba melakukan upaya perbaikan pembelajaran melalui Penelitian Tindakan Kelas (PTK) dengan judul penelitian "Peningkatan Kualitas Pembelajaran Tematik Dengan Model Discovery Learning Melalui Zoom Meeting Pada Siswa Kelas VA SDN Legok Kecamatan Kebasen Kabupaten Banyumas Tahun Pelajaran 2020/2021".

Berdasarkan latar belakang masalah, maka dirumuskan masalah sebagai fokus penelitian perbaikan pembelajaran yaitu "Apakah penerapan Model Discovery Learning melalui Zoom Meeting dapat meningkatkan kualitas pembelajaran tematik pada siswa Kelas VA SDN Legok, Kecamatan Kebasen, Kabupaten Banyumas?

Tujuan penelitian ini adalah untuk meningkatkan Kualitas Pembelajaran Tematik dengan Model Discovery Learning melalui Zoom Meeting pada siswa kelas V A SDN Legok, Kecamatan Kebasen, Kabupaten Banyumas.

\section{METODE}

Jenis penelitian yang digunakan adalah penelitian tindakan kelas. Penelitian ini merupakan penelitian tindakan kelas (PTK) yang dilaksanakan dalam 2 siklus, setiap siklus terdiri dari tahap perencanaan, pelaksanaan, observasi, dan refleksi. Penelitian ini dilakukan di kelas VA SDN Legok Kecamatan Kebasen Kabupaten Banyumas, dengan jumlah 21 siswa terdiri dari 12 siswa laki-laki dan 9 siswa perempuan. Penelitian ini dilaksanakan di SDN Legok Kebasen pada tanggal 22 Oktober 2020 dan 2 November 2020.. Data yang dikumpulkan adalah data kualitatif dan kuantitatif. Data kuantitatif ini diperoleh dari hasil belajar siswa dalam pembelajaran tematik melalui model Discovery Learning. Data kualitatif menurut Sanjaya (2013: 85) adalah data yang berhubungan dengan kualitas tertentu seperti baik, sedang, dan kurang. Data kualitatif berupa deskripsi kegiatan pembelajaran yang diperoleh dari hasil observasi dengan menggunakan lembar pengamatan keterampilan guru, aktivitas siswa, catatan lapangan, serta wawancara dengan kolaborator selama proses pembelajaran tematik melalui model Discovery Learning yang kemudian dikategorikan menjadi beberapa kriteria, yaitu: sangat baik (A), baik (B), cukup (C), dan kurang (D). Sumber data dalam penelitian ini adalah siswa kelas VA SDN Legok dan teman sejawat sebagai observer selama pelaksanaan perbaikan pembelajaran. Teknik pengumpulan data yaitu berupa tes dan non tes. 


\section{HASIL DAN PEMBAHASAN}

Berdasarkan analisis hasil penelitian yang telah diuraikan maka pembahasan pada penelitian ini sebagai berikut :

Tabel 1. Data Peningkatan Kualitas Pembelajaran Tematik

\begin{tabular}{llll}
$\begin{array}{l}\text { Kegiatan } \\
\text { Pembelajaran }\end{array}$ & Aktivitas Guru & Aktivitas Siswa & Hasil Belajar Siswa \\
\hline Studi Awal & 25 & 23,86 & 61,43 \\
Siklus I & 28 & 24,95 & 70,00 \\
Siklus II & 32 & 27,38 & 75,24 \\
\hline
\end{tabular}

Dari tabel di atas menunjukan bahwa kualitas pembelajaran tematik pada siswa kelas VA SD Negeri Legok Kebasen dengan menggunakan model pembelajaran discovery learning telah menunjukan peningkatan yang signifikan. Kondisi kelas terlihat lebih hidup dan pembelajaran lebih menyenangkan karena anak terlibat langsung dalam pembelajaran walaupun secara daring. Berbagai kekurangan dalam proses pembelajaran yang dilaksanakan guru dalam siklus I telah diantisipasi pada siklus II sehingga dapat dilihat pada siklus II pembelajaran dapat berlangusng lebih hidup dan hasil belajar peserta didik lebih meningkat.

Dari hasil perbaikan diatas dapat disimpulkan bahwa penerapan model discovery learning sangat tepat dan relevan untuk pembelajaran tematik pada peserta didik kelas V SD Negeri Legok. Hal ini dapat dibuktikan dari perbaikan siklus ke siklus hasil belajar siswa mengalami peningkatan. Proses pembelajaran yang terjadi dengan melibtakan siswa sehingga berdampak terhadap kemajuan belajar. Keberhasilan dan hasil belajar yang dicapai peserta didik mmbuktikan adanya relevansi penggunaan model discovery learning untuk Pembelajaran tematik sesuai dengan pendapat Hamdani (2011: 194)

\section{SIMPULAN}

Berdasarkan hasil analisis dari Prasiklus sampai dengan siklus kedua, dapat disimpulkan bahwa penerapan model Discovery Learning dapat meningkatkan kualitas pembelajaran pada siswa kelas VA SDN Legok Kecamatan Kebasen Kabupaten Banyumas. Dampak Penerapan model Discovery Learning model Discovery Learning melalui Zoom Meeting dapat meningkatkan keterampilan guru, aktivitas siswa, dan hasil belajar siswa. Berdasarkan kesimpulan ini, maka saran yang dapat diberikan yaitu:

1) Pembelajaran dengan model Discovery Learning melalui Zoom Meeting diperlukan perencanaan yang matang

2) Peningkatan aktivitas siswa, dapat dilakukan guru melalui pemberian motivasi dan penguatan agar siswa berperan aktif dalam pembelajaran, guru juga perlu mengadakan pendekatan individual terhadap siswa agar lebih berani berpendapat dan bertanya.

3) Diharapkan aktivitas siswa lebih mengembangkan cara belajar siswa aktif dengan menemukan dan menyelidiki informasi baru secara mandiri, meningkatkan kemampuan berpikir kritis dan pemecahan masalah untuk meningkatkan hasil belajar siswa.

4) Untuk peneliti, selanjutnya dapat melakukan penelitian tentang iklim pembelajaran, materi pembelajaran, dan media pembelajaran menggunakan instrumen yang relevan karena dalam penelitian ini belum meneliti hal tersebut. 
DAFTAR PUSTAKA

AgusTianasari, Candra Diah. Peningkatan Kualitas Pembelajaran IPS Melalui Model Discovery Learning Berbantuan Media Audiovisual Pada Siswa Kelas VB SDN Ngaliyan 01 Semarang.Diunduh tanggal 13 Oktober 2020. http://lib.unnes.ac.id/21661/1/1401411246-s.pdf

Arikunto, S., Suhardjono, \& Supardi. (2010). Penelitian Tindakan Kelas. Jakarta: Bumi Aksara.

Bertema - Sintaks Sintak model Discovery Learning Dalam Pembelajaran. Diunduh 20 Oktober $2020 \mathrm{https}: / /$ bertema.com/sintaks-model-discovery-learning.

Hamdani. (2011). Strategi Belajar Mengajar. Bandung: Pustaka Setia Universitas Terbuka.

Idcloudhost.Mengenal Aplikasi Zoom: Cara Install dan Fitur-fitur Zoom Meeting.

Diunduh 13 Oktober 2020. https://idcloudhost.com/mengenal-aplikasi-zoomcara-install-dan-fitur-fitur-zoom-meeting-lengkap/

Kemendikbud. (2013). Kerangka Dasar Kurikulum 2013. Jakarta: Kementerian Pendidikan dan Kebudayaan tahun 2013 Badan Standar Nasional Pendidikan. Diunduh 20 Oktober 2020 http://edutaka.blogspot.com/2015/03/pembelajarantematik.html

Kemmis , S., \& McTaggart, R. (1997). The action research planner. Deaken University.

PG Dikdas - Implementasi Kurikulum 2013 menurut Permendikbud Nomor 22 Tahun 2016 . Diunduh 20 Oktober 2020 http://pgdikdas.kemdikbud.go.id/read news/mengenal-model-pembelajaran-discovery-learning

Rusman. (2011). Model-Model Pembelajaran: Membangun Profesinalisme Guru. Jakarta: Rajawali Pers.

Suprijono, \& Agus. (2012). Cooperative Learning: Teori dan Aplikasi PAIKEM. Yogyakarta: Pustaka Pelajar.

Winataputra, \& S, U. (2008). Teori Belajar dan Pembelajaran. Jakarta. 